\title{
Retain womb in retained placenta: hysterotomy for retained bilobed placenta in a preterm angular pregnancy
}

\author{
Sapna Vinit Amin, Anjurani Siddesh, Sunanda Baratnur, Shripad S. Hebbar*
}

Department of Obstetrics \& Gynaecology, Kasturba Medical College, Manipal University, Manipal-576104, Udupi, Karnataka, India

Received: 2 September 2014

Accepted: 19 September 2014

\section{*Correspondence:}

Dr. Shripad S. Hebbar,

E-mail: drshripadhebbar@yahoo.co.in

Copyright: $\odot$ the author(s), publisher and licensee Medip Academy. This is an open-access article distributed under the terms of the Creative Commons Attribution Non-Commercial License, which permits unrestricted non-commercial use, distribution, and reproduction in any medium, provided the original work is properly cited.

\begin{abstract}
Angular pregnancy is a unique condition, which may be associated with both foetal and placental abnormalities, as well as preterm labour and retained placenta. Ultrasound is a useful tool in deciding feasibility of manual removal placenta by ruling out adherent placenta. A twenty five years primipara, five hours following preterm vaginal delivery, at 31 weeks of gestation presented with retained placenta. Uterus was well retracted with minimal bleeding, on trans-abdominal ultrasonography placenta accreta was ruled out. After stabilising, she had hysterotomy and placenta was removed which was bilobed. Neonate had cardiac and renal anomaly and succumbed at the end of one month of life. In young women prime priority is to preserve the uterus, by conservative approach as in our case.
\end{abstract}

Keywords: Angular pregnancy, Hysterotomy, Retained placenta, Manual removal of placenta

\section{INTRODUCTION}

Angular pregnancy refers to implantation of the embryo just medial to utero tubal junction in the lateral angle of uterine cavity which is different from cornual pregnancy and interstitial pregnancy. It is a rare entity and can be associated with foetal or placental abnormalities. Obstetric problems such as preterm labour and third stage complications, for e.g., retained placenta are well known. Manual removal placenta may be difficult in such situation because of inaccessibility or possible association with placenta accreta. We present one such case which required hysterotomy for removal of retained placenta.

\section{CASE REPORT}

A 25 year primipara was referred after preterm vaginal delivery with retained placenta and failed manual removal of placenta. She was referred to our centre with suspicion of adherent placenta.
On antenatal anomaly scan, foetus was detected to have bilateral hydronephrosis (due to probable posterior urethral valve). Otherwise her antenatal period was so far uneventful. She had preterm labour at 31 weeks and delivered male baby weighing $1.8 \mathrm{~kg}$. As placenta was retained and attempts to deliver it by manually were failed and resulted in snapping of the cord and by the time patient arrived at our hospital ten hours had elapsed.

On examination, she had tachycardia and pallor. Uterus was 24 weeks size, well retracted and minimal vaginal bleeding was noted. Umbilical cord was not seen.

Ultrasonography showed entire placenta attached to uterus with no signs of accreta. Laboratory findings were haemoglobin - $6 \mathrm{gm} \%$ with deranged coagulation profile.

After stabilising her, manual removal of placenta was tried under general anaesthesia which was unsuccessful. There was no evidence of hour glass uterus which could be one of the causes of retained placenta, which 
sometimes may be iatrogenic. Decision for hysterotomy was taken. Per-op, uterus was well contracted with a bulge on left cornual region with thinning of overlying myometrium (Figure 1).

Hysterotomy was done in the lower uterine segment, keeping in mind that lower segment incision would have resulted in strong scar during the healing phase, favouring successful outcome in future pregnancy. In spite of open approach, there was great difficulty in removing the placenta. Placenta was found to be bi-lobed.

Figure $2 \& 3$ show the maternal and foetal surfaces of the placenta respectively. She received blood and blood components. Broad spectrum antibiotics and oxytocics were given. Post-operative period was uneventful. Baby was diagnosed to have bilateral hydronephrosis and congenital heart disease, Atrial Septal Defect (ASD) with left to right shunt and died after one month.

One and half years later she came with 8 weeks gestation. Transvaginal scan showed single live foetus corresponding to the period of gestation, but patient was lost for further follow up.

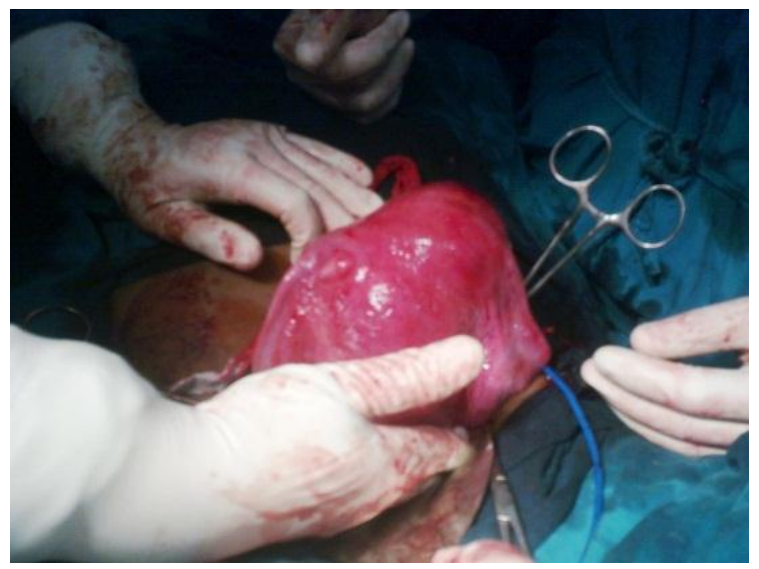

Figure 1: Left fundal bulge due to angular placentation.

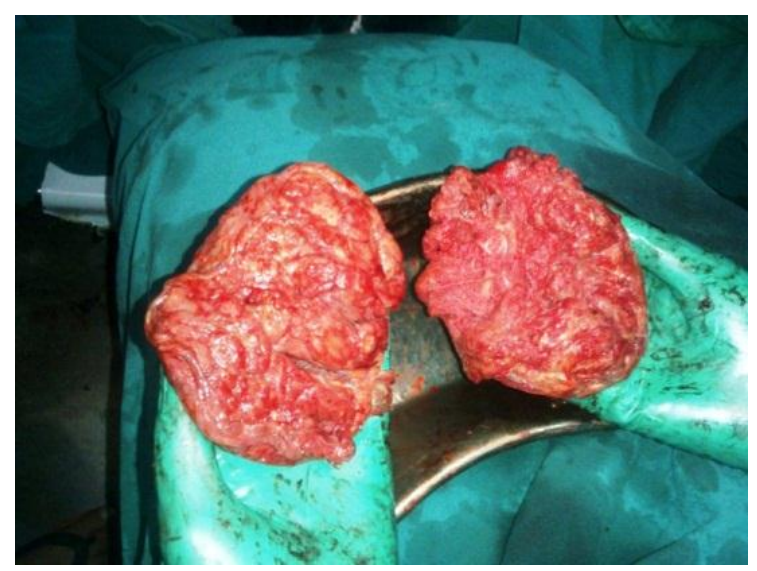

Figure 2: Bilobed placenta - maternal surface.

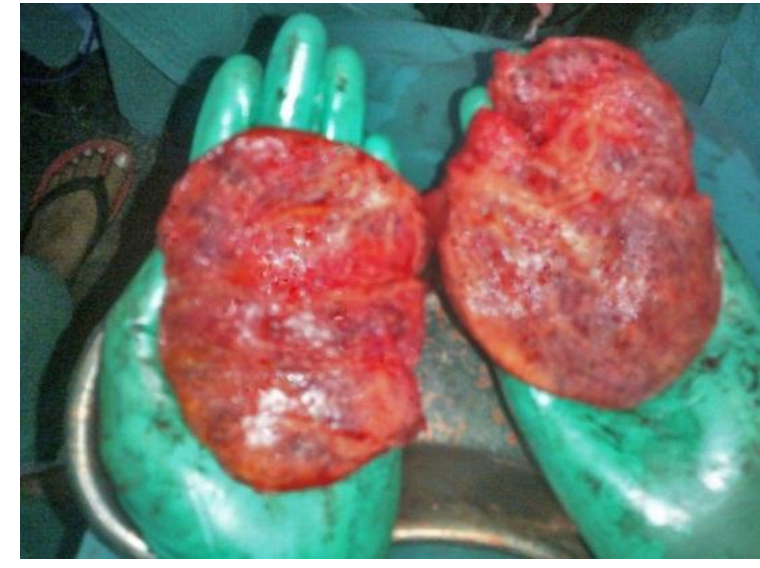

Figure 3: Bilobed placenta - foetal surface.

\section{DISCUSSION}

Retained placenta in angular pregnancy may be inaccessible due to its position during manual removal of placenta. ${ }^{1}$ In absence of adherent placenta hourglass contraction of uterus is rare but might be a possibility. ${ }^{2}$ If there is no postpartum haemorrhage (PPH) placenta may be left in situ, but even this carries complications such as requirement of methotrexate, secondary $\mathrm{PPH}$, hysterectomy, sepsis and prolonged hospital stay. In our case, since she was bleeding, decision to do hysterotomy was made.

Angular pregnancy may be associated with foetal and placental abnormalities and can cause preterm labour, retained placenta, PPH and rupture of uterus3. Irrespective of parity, whether primi or multi, every attempt should be made to avoid hysterectomy. On reviewing the literature, there are very few cited articles on angular pregnancy. ${ }^{4-6}$ In these cases hysterotomy was done to remove retained placenta.

Angular pregnancy requiring hysterotomy makes it a rare entity which, if not managed can lead to devastating complications like haemorrhage, sepsis etc. ${ }^{7-9}$ In these cases hysterotomy and timely correction of blood loss with components may save the uterus for future pregnancy.

\section{CONCLUSION}

Antenatal detection of angular placenta and placental abnormalities is important in anticipating preterm labour and retained placenta. Conservative surgical option should be kept in mind for retaining further reproductive function.

\section{Learning points}

- Angular insertion of placenta when detected during obstetric scan, one should keep in mind possibility of preterm labour and steroid prophylaxis for lung maturity is warranted. 
- There is high chance of retained placenta; possibility of placenta accreta should be ruled out beforehand.

- Manual removal of placenta through vaginal route may be unsuccessful; however one should resort to hysterotomy to preserve the reproductive function.

\section{Funding: No funding sources}

Conflict of interest: None declared

Ethical approval: Not required

\section{REFERENCES}

1. Deckers EA, Stamm CA, Naake VL, Dunn TS, McFee JG. Hysterotomy for retained placenta in a term angular pregnancy: a case report. J Reprod Med. 2000;45(2):153-5.

2. Burmester AJ. Hour-glass contraction of the uterus, and retained placenta. Lancet. 1844;44(1113):404.

3. Shekhar S, Verma S, Motey R, Kaushal R. Hysterotomy for retained placenta with imminent uterine rupture in a preterm angular pregnancy. Acta Obstet Gynaecol Scand. 2010;89(12):1615-6.

4. Mayer RB, Yaman C, Ebner T, Shebl O, Sommergruber M, Hartl J, et al. Ectopic pregnancies with unusual location and an angular pregnancy: report of eight cases. Wien Klin Wochenschr. 2012;124(5-6):193-7.

5. Kwon JY, Hwang SJ, Shin JE, Yoon WS, Shin JC, Park IY. Two cases of angular pregnancy complicated by preterm labor and placental abruption at mid-pregnancy. J Obstet Gynaecol Res. 2011;37(7):958-62.

6. Alves JA, Alves NG, Alencar Júnior CA, Feitosa FE, da Silva Costa F. Term angular pregnancy: Successful expectant management. J Obstet Gynaecol Res. 2011;37(6):641-4.

7. Weeks AD. The retained placenta. Afr Health Sci. 2001;1(1):36-41.

8. Chhabra S, Dhorey M. Retained placenta continues to be fatal but frequency can be reduced. J Obstet Gynaecol. 2002;22(6):630-3.

9. Agwu UM, Umeora OU, Ejikeme BN, Egwuatu VE. Retained placenta aspect of clinical management in a tertiary health institution in Nigeria. Niger $\mathbf{J}$ Med. 2008;17(2):146-9.

DOI: $10.5455 / 2320-1770 . i j r \operatorname{cog} 20141251$

Cite this article as: Amin SV, Siddesh A, Baratnur S, Hebbar SS. Retain womb in retained placenta: hysterotomy for retained bilobed placenta in a preterm angular pregnancy. Int J Reprod Contracept Obstet Gynecol 2014;3:1122-4. 